\title{
Finite Element Analysis with COMSOL Code for Air Flow and Thermal Convection in Sealed Attic Spaces with Experimental Validation
}

\author{
Antonio Campo*, ${ }^{*}$, and Jaime Sieres ${ }^{b}$ \\ ${ }^{a}$ Department of Environmental Engineering, Faculty of Engineering, University of Vermont, Burlington, VT 05405, USA \\ ${ }^{b}$ Área de Máquinas y Motores Térmicos, Escuela de Ingeniería Industrial, Universidad de Vigo, Campus Universitario \\ Lagoas-Marcosende, 36310 Vigo, Spain
}

\begin{abstract}
The scope of the present paper is concerned with the numerical prediction of the confined air flow characteristics and thermal convection patterns in sealed attic spaces in roofs with upper inverted V-shapes and horizontal suspended ceilings of conventional houses and buildings. For these isosceles triangular cavities, two relevant cases involve prescribed wall temperatures wherein the bottom base wall is cooled/heated and the upper two inclined walls are symmetrically heated/cooled during the summer and winter seasons. Based on finite element analysis, the COMSOL code is implemented to perform numerical solutions of the two-dimensional system of coupled Navier-Stokes-Boussinesq and energy equations. The computational domain is made coincident with the physical domain to handle potential non-symmetric velocities and non-symmetric temperatures that may occur when exposed to vigorous air flows. The numerical solution via finite elements provides the two velocity fields $\mathrm{u}(\mathrm{x}, \mathrm{y}), \mathrm{v}(\mathrm{x}, \mathrm{y})$ and the temperature field $\mathrm{T}(\mathrm{x}, \mathrm{y})$ for the confined air flows. Overall, the target design quantity is the mean wall heat fluxes $\overline{q_{w}}$ varying with the attic aspect ratio and the temperature difference at two opposing walls. The predicted $\overline{q_{w}}$ values match the experimental measurements for the two distinct cases related to summer and winter seasons. At the end, comprehensive correlation equations are constructed for the quantification of the mean Nusselt number in terms of the Grashof number and the attic aspect ratio, which could be used in building science research.
\end{abstract}

Keywords: Sealed Attics of Houses And Buildings, Circulatory Air Flow, Thermal Convection, Finite Element Analysis, COMSOL Code, Experimental Measurements)

\section{Introduction}

In reference to stationary cavities containing fluids, thermal convective currents are induced and sustained when fixed temperature differences are applied at two or more walls of the cavity. This scenario represents an important class of problems in several branches of technology, such as building physics, engineering, geophysics, environmental sciences, etc. The subject of thermal convection cavity flows has been studied analytically, numerically and experimentally by a multitude of investigators over the world for numerous years. These investigations have been normally channeled through correlation equations for the prediction of the mean convection coefficients in terms of geometric and thermal quantities. With regards to internal thermal convection, chapters by Raithby and Hollands [1] and Jaluria [2] in heat transfer handbooks present correlation equations for the mean convection coefficient associated with six cavities of various shapes: vertical rectangular, horizontal rectangular, square, vertical annuli, horizontal annuli and spherical shells. Traditionally, the format of the correlation equations specifies the mean Nusselt number varying with the Grashof number, the Prandtl number and the

${ }^{*}$ Corresponding author Tel.: (210) 458-5516

Fax: (210) 458-6504; E-mail: campanto@yahoo.com

(C) 2016 International Association for Sharing Knowledge and Sustainability

DOI: $10.5383 /$ ijtee.12.01.005 
cavity aspect ratio. Unfortunately, correlation equations for other important cavity shapes are absent in these handbooks. In particular, the isosceles triangular cavity is of importance because it represents typical sealed attic spaces of houses and buildings having horizontal suspended ceilings and upper inverted V-roofs. For a given house of building roof, a steeper roof requires a larger area of roof material and forms a larger and higher attic space. Two contrasting heating/cooling conditions are linked to the isosceles triangular cavity of variable height, which take place during summer and winter seasons

The importance of the attic heat transfer problem ascribes to the American Society of Heating, Refrigeration and Air Conditioning Engineers model (ASHRAE Handbook [3]), which stipulates that $46 \%$ of the heat load in houses or buildings located in hot and cold climates goes through the roof. In energyconscious industrialized countries, it is a requirement for houses and buildings to be energy efficient. This implies that the energy consumption for heating in the winter and cooling in the summer must be minimized. As stated by Davis [4], year-long numerical simulations of house and building attics are important for determining accurately the heat loads for heating in winter and air conditioning in summer. Therefore, it is natural to expect that attic aspect ratio, coupled with air flows in attic space, will affect the energy performance of a house or building. With this information, design, changes and retrofits of attics are plausible for economical energy usage.

As revealed in a literature review, most of past studies on attic heat transfer have assumed that the air flow is symmetric with respect to the vertical mid-plane in a sealed attic, i.e., in a long horizontal right-triangular enclosure. The three early references on these analyses are those by Akinsete and Coleman [5], Poulikakos and Bejan [6] and Salmun [7]. However, it is worth emphasizing that the symmetric air flow solutions reported here are valid for low Grashof numbers only. For moderate-to-high Grashof numbers, the assumption of a partial right-triangular enclosure fails and the full isosceles triangular cavities must be considered. In this regard, Holtzman et al. [8] demonstrated that the incipient symmetric buoyant air flows disappear and metamorphose gradually into strong asymmetric buoyant air flows.

The present paper addresses air flow and thermal convection confined to sealed attic spaces heated/cooled at the bottom base wall and symmetrically cooled/heated at the two upper inclined walls. The primary aim of the paper is to determine the detailed velocity and temperature fields of the buoyant air trapped inside isosceles triangular cavities under two different heating/cooling scenarios to facilitate heat load calculations on a year basis. The finite element analysis code COMSOL is implemented to numerically solve the coupled system of two-dimensional Navier-Stokes-Boussinesq and energy equations in the nonregular cavities when subject to the no-slip velocity boundary condition and prescribed temperature boundary conditions. For engineering applications, the numerical temperature fields are channeled through the mean wall heat fluxes $\overline{\mathrm{q}_{\mathrm{w}}}$ varying with the attic shape and the temperature difference $\mathrm{TH}-\mathrm{TC}$ imposed at the opposing walls. As a culmination, a comprehensive correlation equation for the the mean Nusselt number is constructed by way of a double-valued function in terms of the Rayleigh number and the aspect ratio A; namely $\overline{\mathrm{Nu}}_{\mathrm{H}}=\mathrm{f}$ ( $\mathrm{RaH}, \mathrm{A})$. The correlation equation is essential for improving our understanding of building performance and/or in developing innovative modeling and computational techniques. The body of the present paper is divided into three main sections. The physical system and the mathematical formulation are described in the first section. The computational procedures with the finite element method linked to the full-scale computational domain are explained in the second section. The third section is devoted to a discussion of the numerical-obtained velocity fields, the temperature field along with the total heat transfer rates for various attic shapes. With regards to total heat transfer rates, detailed one-to-one validations with experimental measurements are included for the two opposing heating/cooling conditions during the summer and winter seasons.

\section{Statement of the Physical System}

A schematic diagram of the cross-section of a sealed attic in houses and buildings is sketched in Fig. 1. Filled with air, this attic space is constructed with an inverted V-roof sitting on top of a horizontal suspended ceiling. Depending upon the season of the year, two opposing situations need to be considered:

Case 1: the base wall is cooled and the two upper inclined walls are symmetrically heated during the summer season

Case 2: the base wall is heated and the two upper inclined walls are symmetrically cooled during the winter season

As mentioned before, early studies on attic heat transfer have assumed that the air flow is symmetric with respect to the vertical mid-plane dividing the attic in half [5-7], resulting in symmetric velocities and temperatures. These results are of limited value because they are valid for low Rayleigh numbers as was demonstrated in [8] that asymmetric conditions for velocities and temperatures are formed for intermediate-to-high Rayleigh numbers when using isosceles triangular cavities.

The relevant assumptions to be invoked in the numerical analysis are listed next. First, the dimension perpendicular to the plane in Fig. 1 is very long, to ignore the end effects, and the problem is predominantly two-dimensional. Second, the powerful three-part Boussinesq approximation is adopted wherein: (1) the density is constant in the mass conservation equation, (2) the density difference term is approximated by a temperature difference term by way of the ideal gas equation of state and (3) the viscosity, specific heat capacity and thermal conductivity in the momentum and energy conservation equations are constant. In this regard, Chenoweth and Paolucci [9] recommended that the Boussinesq approximation provides accurate estimates of the total heat transfer across differentially heated square cavities for wall temperature ratios satisfying the inequality $\left(\mathrm{T}_{\mathrm{H}}-\mathrm{T}_{\mathrm{C}}\right) / \mathrm{T}_{\mathrm{m}}<0.6$. In here, $\mathrm{T}_{\mathrm{H}}$ is the hot wall temperature, $\mathrm{T}_{\mathrm{C}}$ is the cold wall temperature and $\mathrm{T}_{\mathrm{m}}=\left(\mathrm{T}_{\mathrm{H}}+\right.$ $\mathrm{T}_{\mathrm{C})} / 2$ stands for the mean fluid temperature. According to this description, the coupled system of two-dimensional Navier-Stokes-Boussinesq and energy equations as taken from Oosthuizen and Naylor [10] are written as:

Mass:

$$
\frac{\partial u}{\partial x}+\frac{\partial \mathrm{v}}{\partial \mathrm{y}}=0
$$

$\mathrm{x}-$ Momentum: 


$$
\rho u \frac{\partial u}{\partial x}+\rho v \frac{\partial u}{\partial y}=-\frac{\partial p}{\partial x}+\mu \frac{\partial^{2} u}{\partial x^{2}}+\mu \frac{\partial^{2} u}{\partial y^{2}}
$$

y-Momentum:

$$
\rho \mathrm{u} \frac{\partial \mathrm{v}}{\partial \mathrm{x}}+\rho \mathrm{v} \frac{\partial \mathrm{v}}{\partial \mathrm{y}}=\mu \frac{\partial^{2} \mathrm{v}}{\partial \mathrm{x}^{2}}+\mu \frac{\partial^{2} \mathrm{v}}{\partial \mathrm{y}^{2}}+\rho \beta\left(\mathrm{T}-\mathrm{T}_{\mathrm{m}}\right)
$$

where the reference temperature $\mathrm{T}_{\mathrm{m}}$ is evaluated at the mean air temperature $\mathrm{T}_{\mathrm{m}}=\left(\mathrm{T}_{\mathrm{H}}+\mathrm{T}_{\mathrm{C}}\right) / 2$.

Energy:

$$
\rho c_{p} u \frac{\partial T}{\partial x}+\rho c_{p} v \frac{\partial T}{\partial y}=k \frac{\partial^{2} T}{\partial x^{2}}+k \frac{\partial^{2} T}{\partial y^{2}}
$$

\subsection{Velocity and Temperature Boundary Conditions}

In compliance with the common idealization where air does not slip at the three walls of the isosceles triangular cavity, the velocity boundary conditions are taken as $\mathrm{u}=\mathrm{v}=0$. However, with regards to the temperature boundary conditions, two options transpire though. First, for Case 1, a cold temperature $T_{C}$ is prescribed at the horizontal base wall and the same hot temperature $\mathrm{T}_{\mathrm{H}}$ is prescribed at the two upper inclined walls for the summer season. Second, for Case 2, a hot temperature $\mathrm{T}_{\mathrm{H}}$ is applied at the horizontal base wall and the same cold temperature $T_{C}$ is applied at the two upper inclined walls for the winter season.

\section{Finite Element Analysis}

A typical attic space in the shape of an isosceles triangular cavity with base $\mathrm{W}$, height $\mathrm{H}$, hypotenuse $\mathrm{L}$ and apex angle $\alpha$ is sketched in Fig. 1a. To be on the safe side, the computational domain is taken as coincident with the physical domain in order to absorb potential nonsymmetric velocities and temperatures that may arise inside the isosceles triangle. Clearly, two controlling quantities that emerge from the coupled system of Navier-Stokes-Boussinesq and energy equations: (1) the aspect ratio $\mathrm{A}=\mathrm{H} / \mathrm{W}$ and (2) the temperature difference $\mathrm{TH}-\mathrm{TC}$, the latter being represented through the heightbased Grashof number GrH.

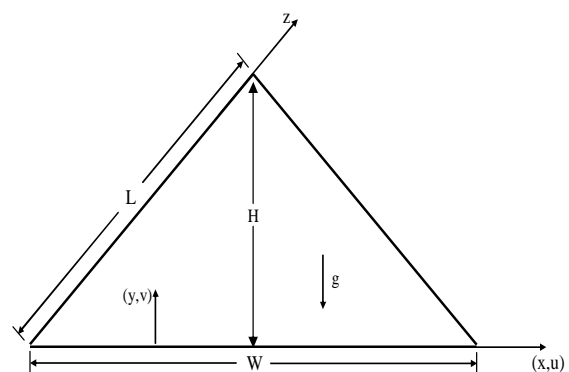

Figure 1. Sketch of the Sealed Attic Space in a House Or Building

The numerical solution of the coupled system of partial differential equations (1)-(4) subject to the proper velocity and temperature boundary conditions supplies the velocity field $\mathrm{u}(\mathrm{x}, \mathrm{y}), \mathrm{v}(\mathrm{x}, \mathrm{y})$ and the temperature field $\mathrm{T}(\mathrm{x}, \mathrm{y})$ of the restrained air for the two cases under study. Based on the definition of the stream function $\psi(\mathrm{x}, \mathrm{y})$, the computed velocity fields' $\mathrm{u}(\mathrm{x}, \mathrm{y}), \mathrm{v}(\mathrm{x}, \mathrm{y})$ are post-processed to determine the streamlines for the air flow:

$\mathrm{u}=\frac{\partial \psi}{\partial \mathrm{y}}, \quad \mathrm{v}=-\frac{\partial \psi}{\partial \mathrm{x}}$

From the temperature field $\mathrm{T}(\mathrm{x}, \mathrm{y})$, the local wall heat flux qw ( $\mathrm{x}$ ) in the interval $0 \leq \mathrm{x} \leq \mathrm{W}$ (defining the base wall) was determined by applying Fourier's law

$$
\mathrm{q}_{\mathrm{w}}(\mathrm{x})=-\left.\mathrm{k} \frac{\partial \mathrm{T}}{\partial \mathrm{y}}\right|_{\mathrm{y}=0}
$$

where the thermal conductivity of air is evaluated at the mean temperature $\mathrm{Tm}=(\mathrm{TH}+\mathrm{TC}) / 2$. This pivotal step gives way to the quantification of the mean wall heat flux $\mathrm{q}_{\mathrm{w}}$ at the base wall

$\overline{\mathrm{q}_{\mathrm{w}}}=\frac{1}{\mathrm{~W}} \int_{0}^{\mathrm{W}} \mathrm{q}_{\mathrm{w}}(\mathrm{x}) \mathrm{dx}$

With this information, the mean convective coefficient $\bar{h}$ is computed frim the definition

$$
\overline{\mathrm{h}}=\frac{\overline{\mathrm{q}_{\mathrm{w}}}}{\mathrm{T}_{\mathrm{H}}-\mathrm{T}_{\mathrm{C}}}
$$

and thereafter equivalent mean Nusselt number is framed with the ratio

$$
\overline{\mathrm{Nu}}_{\mathrm{H}}=\frac{\mathrm{H} \overline{\mathrm{h}}}{\mathrm{k}}=\frac{\mathrm{H}}{\mathrm{k}} \frac{\overline{\mathrm{q}_{\mathrm{w}}}}{\left(\mathrm{T}_{\mathrm{H}}-\mathrm{T}_{\mathrm{C}}\right)}
$$


Considerable advances have been made in the study of thermally-induced convection in cavities of arbitrary shape thanks to the development of potent grid generation software and efficient computational methods for solving coupled systems of Navier-Stokes-Boussinesq and energy equations (Tannehill et al. [11]). While the Finite Difference Method (FDM) in its basic form is restricted to rectangular bodies and simple alterations thereof, the handling of complex bodies and/or irregular boundaries (like in attic configurations) with the Finite Element Method (FEM) is rather straightforward (Zienkiewicz et al. [12]) The coupled system of partial differential equations (1) - (4) and the proper boundary conditions was solved numerically using the commercial finite element code COMSOL Multiphysics version 3.5 [13], in conjunction with the numerical solver UMFPACK [14]. COMSOL is an advanced software package for modeling and simulating physical processes describable by a coupled/uncoupled system of partial differential equations. To start with, the numerical validation of COMSOL was done against the popular benchmark solution for thermal convection in a standard square cavity with a hot vertical wall, a cold vertical wall and two insulated horizontal walls, which was developed by Vahl Davis [15].Knowingly that the vertical velocity $\mathrm{v}$ is the crucial variable in the analysis of cavity flows because the velocity and temperature fields are interweaved, it was found that the numerical estimates for the dimensionless velocity Vmax are within five percent of the results reported in [15]. The convergence criteria of the dimensionless velocity and temperature fields was overseen with the following norm

$$
\frac{1}{\phi_{\max }} \sqrt{\sum_{i=1}^{\mathrm{N}}\left(\phi_{i}^{\mathrm{n}+1}-\phi_{i}^{\mathrm{n}}\right)^{2}} \leq \varepsilon
$$

where $\phi \mathrm{i}$ is a dummy variable (velocity $\mathrm{u}$ and $\mathrm{v}$ or temperature T) whose typical error value is $\varepsilon=10-4$. It was detected that further decreases in $\varepsilon$ do not cause any significant changes in the numerical results. Therefore, the success of the COMSOL code in simulating natural convection in square cavities with air has been demonstrated. In addition, it is confirmed that the estimates for the mean convective coefficient $\bar{h}$ (the ultimate thermal quantity in the analysis) compared reasonably well with the numbers found in Ref. [15].

After nondimensionalizing the variables dealing with geometric, velocity and temperature excess with the respective scales $\mathrm{H}, v / \mathrm{H}$ and $\mathrm{TH}-\mathrm{TC}$, the problem formulation is dependent upon two parameters: the apex angle, $\alpha$, and the Rayleigh number, $\mathrm{RaH}$, because $\operatorname{Pr}=0.7$ for air. A sensitivity analysis of the computational grid was done with three meshes consisting of roughly 2,400, 6,300 and 10,300 triangular elements in order to choose the optimal grid size. In all cases, care was taken to increase the density of triangular elements in vulnerable areas where steep velocity and temperature gradients would occur, such as near the walls and vertices in the attic. Based on a sequence of numerical experiments, it was decided that a mesh with 3,600 triangular elements was adequate and sufficiently fine, so that the velocity and temperature predictions were found to be accurate, dependable and consistent. Related information is available in Table 1.

Table 1. Comparison of Representative Quantities Related to Natural Convection in A Differentially Heated Square Cavity at A High $\mathbf{R a}_{\mathbf{h}}=$ $10^{6}$

\begin{tabular}{|c|c|c|c|}
\hline \multicolumn{2}{|c|}{ Dimensionless } & \multirow[b]{2}{*}{ de Vahl Davis [15] } & \multirow[b]{2}{*}{ Error $\%$} \\
\hline Quantity & $\begin{array}{r}\text { Present } \\
\text { Work }\end{array}$ & & \\
\hline $\mathrm{U}_{\max }$ & 68.81 & 64.630 & 6.47 \\
\hline $\mathrm{Y}$ & 0.87 & 0.850 & 2.35 \\
\hline $\mathrm{V}_{\max }$ & 221.80 & 217.360 & 2.04 \\
\hline $\mathrm{X}$ & 0.04 & 0.038 & 5.26 \\
\hline $\mathrm{Nu}_{\mathrm{H}, \max }$ & 17.87 & 17.925 & -0.31 \\
\hline $\mathrm{Y}$ & 0.04 & 0.038 & 5.26 \\
\hline $\mathrm{Nu}_{\mathrm{H}, \min }$ & 1.02 & 0.989 & 3.13 \\
\hline $\mathrm{Y}$ & 0.99 & 1.000 & -1 \\
\hline $\mathrm{Nu}_{\mathrm{H}}$ & 8.75 & 8.799 & -0.56 \\
\hline
\end{tabular}

For visualization purposes, the optimal mesh to be adopted is illustrated in Fig. 2. Further convergence was assessed by monitoring the computed magnitudes of the mean convective coefficient $\bar{h}$ along the base wall of the isosceles triangular cavity forming the attics.

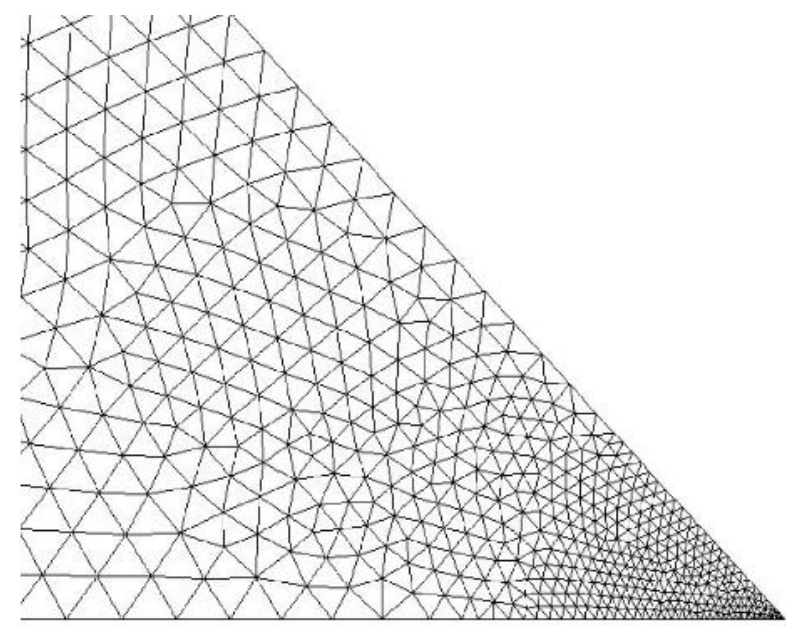

Figure 2. Computational Domain Coincident With the Physical Domain and Typical Mesh Layout For Finite Element Analysis 
To run the COMSOL code, we chose an attic with an intermediate apex angle $\alpha=45^{\circ}$ as cited in [16] as a logical representation of the three different attic configurations. The Grashof numbers $\mathrm{GrH}$ responds to two primary quantities: the attic height $\mathrm{H}$ and the impressed wall-to-wall temperature difference TH - TC. For convenience, we decided to fix the temperature difference at $\mathrm{TH}-\mathrm{TC}=26^{\circ} \mathrm{C}$ and vary the attic height $\mathrm{H}$ to come up with a desired sequence of Grashof numbers, $\mathrm{GrH}$.

\section{Experimental Measurements}

In a series of experiments conducted by Flack [16], three different attics in the form of triangular isosceles cavities of variable height $\mathrm{H}$ having three different apex angles $\alpha=30^{\circ}, 45^{\circ}$ and $60^{\circ}$ were tested in a thermofluids laboratory. The working fluid was air. Details about the design, fabrication and testing of the experimental setup along with the adopted measuring techniques for velocities, temperatures and wall heat fluxes are found in this reference. The air flow and thermal convection in the isosceles triangular enclosures was subject to 1) simultaneous heating from the base and cooling from the two inclined surfaces (winter condition) and 2) simultaneous cooling from the base and heating from the two inclined surfaces (summer condition).

\section{Presentation of Numerical Results}

Several figures have been prepared to provide detailed information for the velocity and temperature distributions. Such information is critical for a better understanding of the fundamental mechanism of momentum and heat transport in the sealed attic spaces for winter and summer seasons.

\subsection{Case 1 - Cold Base Wall and Hot Upper Inclined Walls}

Fluid motion was set up by symmetrically heating the two upper inclined walls of the attic space while the base wall was maintained cold. When examining Fig. 3a, we observe a contour plot of the stream functions associated with $\mathrm{GrH}=105$ where two symmetric counter rotating vortices exist on each side of the isosceles triangular cavity. As evident from the stream function gradient, the velocity will be the highest near the bottom corners of the triangle, where the gradient between the stream functions is the largest. The high velocity moves the fluid from the bottom of the triangle up through the center. In contrast to the corner of the isosceles triangle, the center of the geometry contains slow moving fluid as shown by the low gradient area in the center of the triangle. When $\mathrm{GrH}$ is increased more than one order of magnitude to $2.84 \times 106$, the qualitative shape of the counter rotating cells in the isosceles triangle remains the same as reflected in Fig. 4a. However, the magnitude of the velocity gradients in the triangle corner increases by one order of magnitude and as a consequence this creates higher fluid velocities. Because the two upper walls are heated and the bottom wall is cooled, regardless of the value of $\mathrm{GrH}$, Case 1 is always stable and the patented stratified temperature profiles in Figs. $3 \mathrm{~b}$ and $4 \mathrm{~b}$ resemble pure conduction situations. Using Ref. [14] involving three apex angles $\alpha=30^{\circ}, 45^{\circ}$ and $60^{\circ}$, Fig. 7 serves to illustrate the excellent parity between the experimental and the numerical values of $\overline{\mathrm{Nu}} \mathrm{H}$, whose magnitude stays around 4.5 The invariance of $\overline{\mathrm{Nu}}$ H with GrH indicates that heat is transported by the conduction mode in the GrH sub-interval.

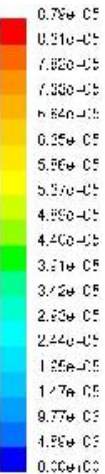

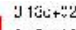

$91 \varepsilon \in 1 \div 2$

: I 11:......

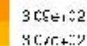

scrir....)

$3 c<i \leqslant 2$

XC:Fe+.:y

$3 c i c+v^{2}$

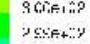

$2 \leq \pi+i 2$

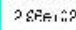

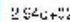

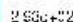

3द $1 \in 1+2$

$2 \xi 1 \in i \leqslant 2$

(3)

$2 \varepsilon \varepsilon+1 \div 2$

ถ⿻丷木,

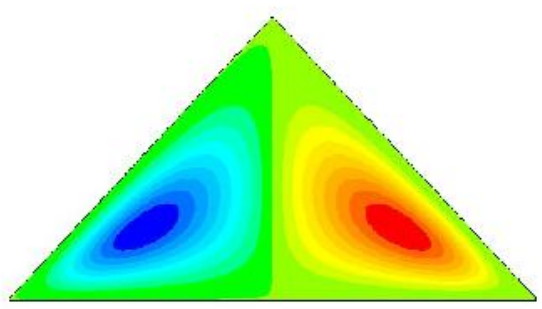

(a)

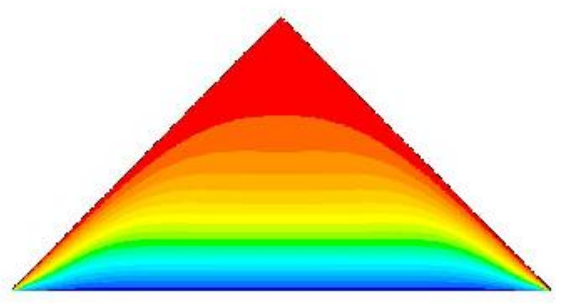

(b)

Figure 3. Plots of Stream Functions And Isotherms For Case 1 Characterized By Gr $\mathbf{r}_{h}=10^{5}$

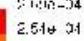

;in:- 34

$2.24 \Rightarrow 31$

DII 21

I inta 24

1. $i$ itu- 34

$1.6 \mathrm{te}$ as

1 4:10:-34

$1.39 \Rightarrow 34$

1. 12401

$1144+-34$

1.0use

1.00-2)

7.160 as
6.970 os

C.9ं日

C. 21 in- 25

2. $20 \%$ ग5

1 4.4e-3:

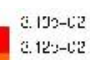

c. $12 \%-122$

$3.034 \mathrm{C} 2$

a חiי ri?

c.uj:-l:

다어글 2

$5.034 \mathrm{C2}$

a $114 \mathrm{rit}:$

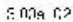

2. $29+\mathrm{C} 2$

2. $9 \mathrm{~F} y \mathrm{C} 2$

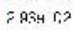

F Ma ri?

¿.व

z. $914 \mathrm{Cl}$

व

$=9,14 \mathrm{r}$ r?

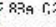

8 870-5.?

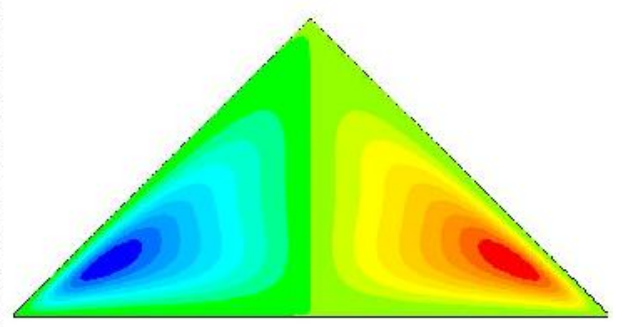

(a)

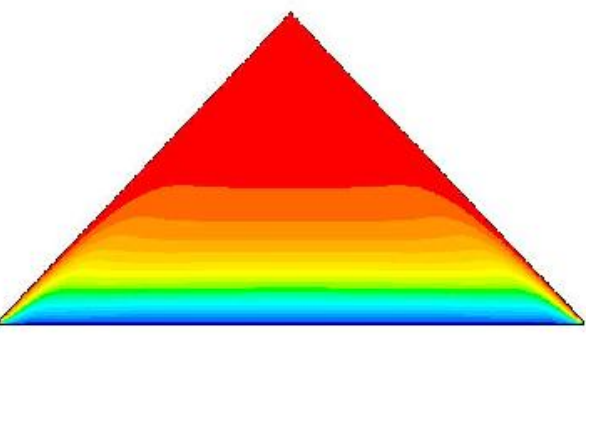

(b)

Figure 4. Plots of Stream Functions And Isotherms For Case 1 Characterized By $\mathrm{Gr}_{\mathrm{h}}=2.84 \times 10^{6}$ 


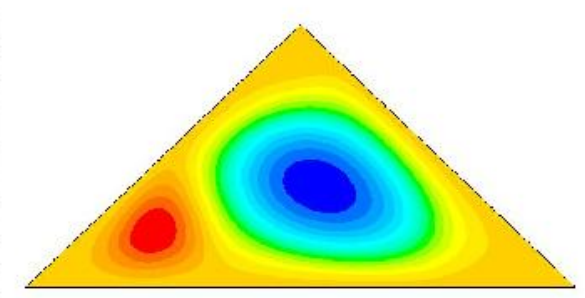

(a)

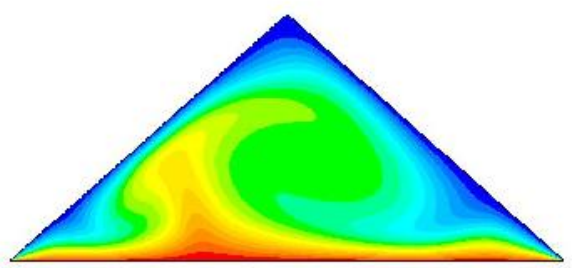

(b)

Figure 5. Plots of Stream Functions And Isotherms For Case 2 Characterized By $\mathrm{Gr}_{\mathrm{h}}=2 \times 10^{5}$
1.3. 3 - 15:
$1.5 \mathrm{AH}$
$1.450-15$
1.34

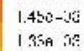
$1.2 \div 40$
1.13923

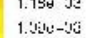
मे
3. $2 \pi+2$
11 I: I:
i.2bu-je

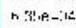
5. H.
$4.5 \mathrm{~s} 0-\mathrm{ik}$
0.50 -30

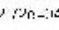
1.31 잔
inisu-its

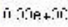
3) 1 (1)
3.cge, 32
S.C. $7 \mathrm{C}+12$
3. $.6 E_{1}, 32$
$3 . C 4 C+32$
31 )
3.드.
8. $\mathrm{COc}+\mathrm{J} 2$
$2.89 \mathrm{e}, \mathrm{j} 2$
$2.57 c+? 2$
$\rightarrow(6+4)+1)$
$284=132$
$7 x^{2}+1$
2.:16135
$2.0 \mathrm{c}+32$

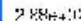
$20 ; 7,1,12$

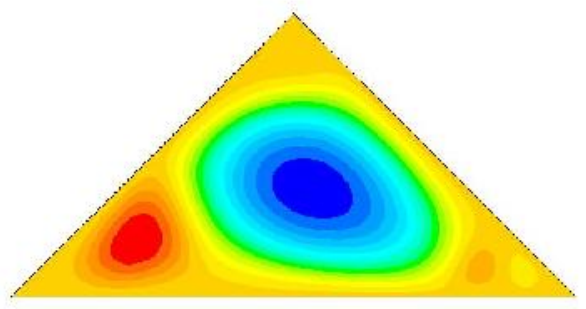

(a)

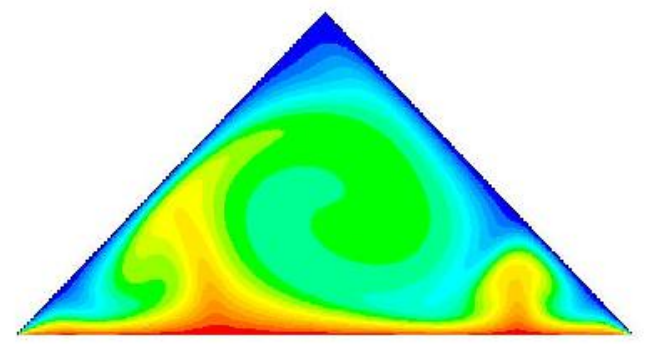

Figure 6. Plots of Stream Functions And Isotherms For Case 2 Characterized By Gr$r_{h}=6.25 \times 10^{5}$
5.2. Case 2: Hot Base Wall \& Cold Upper Inclined Walls At small values of Grashof numbers GrH lying below the critical $\mathrm{GrH}, \mathrm{C}$, there is little increase in the heat transfer over that due to conduction. As $\mathrm{GrH}$ increases, the evolution of flow regimes include conduction, transition and boundary layer flow, resulting in a continuous increment in the mean convective coefficient, $\overline{\mathrm{h}}$ that is significant. The conduction regime is characterized by a linear temperature variation in the central region of the isosceles triangular cavity. In the boundary layer regime, thin boundary layers appear along the heated wall with temperature uniformity between the lower and upper boundary layers. In addition, it is verifiable that in the aspect ratio limit A $\rightarrow 0$, the air circulation consists of two elongated cells implying that the heat transfer is dominated by conduction. In this particular case, the numerical computations were performed for two Grashof numbers, namely $\mathrm{GrH}=2 \times 105$ and $6.25 \times 105$. In sharp contrast with Figs. $3 \mathrm{a}$ and $4 \mathrm{a}$, the symmetry between the two counter rotating vortices disappears when the prescribed temperature boundary conditions are reversed. First, in Fig. 5a linked to $\mathrm{GrH}=2 \times 105$, one cell increases in size and moves from the corner of the triangle towards the center while the second cell remains in the corner, but diminishes in size. The high velocity area now exists between the two cells where the stream function gradient is high. This large velocity moves warm air from the bottom horizontal wall upwards toward the inclined walls. As the air moves upwards, the large clockwise rotating vortex in the center of the triangle turns the fluid. The turning upward movement can be seen in the temperature contours in Fig. 5b. Second, as GrH is increased to 6.25 x 105, three rotational cells exist as evidenced in Fig 6a. Two of the cells are in a similar location to Fig. 5a, but a new cell forms in the right hand corner. This new cell again moves warm air adjacent to the bottom wall upward and helps increase the overall heat transfer from the bottom wall. In addition to the third vortex formation, the strength of the original vortices is higher for the larger Grashof number. In fact, as $\mathrm{GrH}$ is strenghtened from $2 \times 105$ to $6.25 \times 105$, the stream function gradient intensifies in magnitude by about one order of magnitude. The direct effect of these three vortices on the temperature field $\mathrm{T}(\mathrm{x}, \mathrm{y})$ can be seen in the pair of Figs. $5 \mathrm{~b}$ and $6 \mathrm{~b}$, where two streams of warm air are diverted upward from the wall. In Fig. 7, it is gratifying to see a good agreement been the numerical-determined and the experimental-measured $\overline{\mathrm{Nu}} \mathrm{H}$ within the bounds of laminar air motion. In the sense of curvefitting, we looked into a generalized approach embracing the three attic shapes used in Ref. [14] with respective apex angles

$\alpha=30^{\circ}, 45^{\circ}$ and $60^{\circ}$. To analyze the collection of $\overline{\mathrm{Nu}}_{\mathrm{H}}, \mathrm{GrH}$, A data, the SAS code [17] was implemented to produce the comprehensive correlation equation

$$
\overline{\mathrm{Nu}}_{\mathrm{H}}=0.286 \mathrm{~A}^{-0.286} \mathrm{Gr}_{\mathrm{H}}{ }^{1 / 4}
$$

with a high correlation coefficient $\mathrm{R} 2 \approx 0.975$ which applies in the large $\mathrm{GrH}$ interval [105, 109]. At this point, it is recognizable that the structure of the correlation equation is consistent with the correlation equations inherent to natural convection in closed spaces as reported in the chapters on natural convection in Refs. [1,2]. At this point, it is worth commenting about the exponents showing up in eq. (11). First, the universal exponent $1 / 4$ in $\mathrm{GrH}$ is prototypical of laminar regimes, connected to either internal or external natural convection flows [1, 2]. Secondly, the negative exponent affecting the aspect ratio A is essentially a trademark for laminar natural convection in vertical rectangular cavities and square cavities $[1,2]$. It is clear that the heat transfer rate across the sealed attic increases with $\mathrm{A}$, the aspect ratio of roof pitch. 


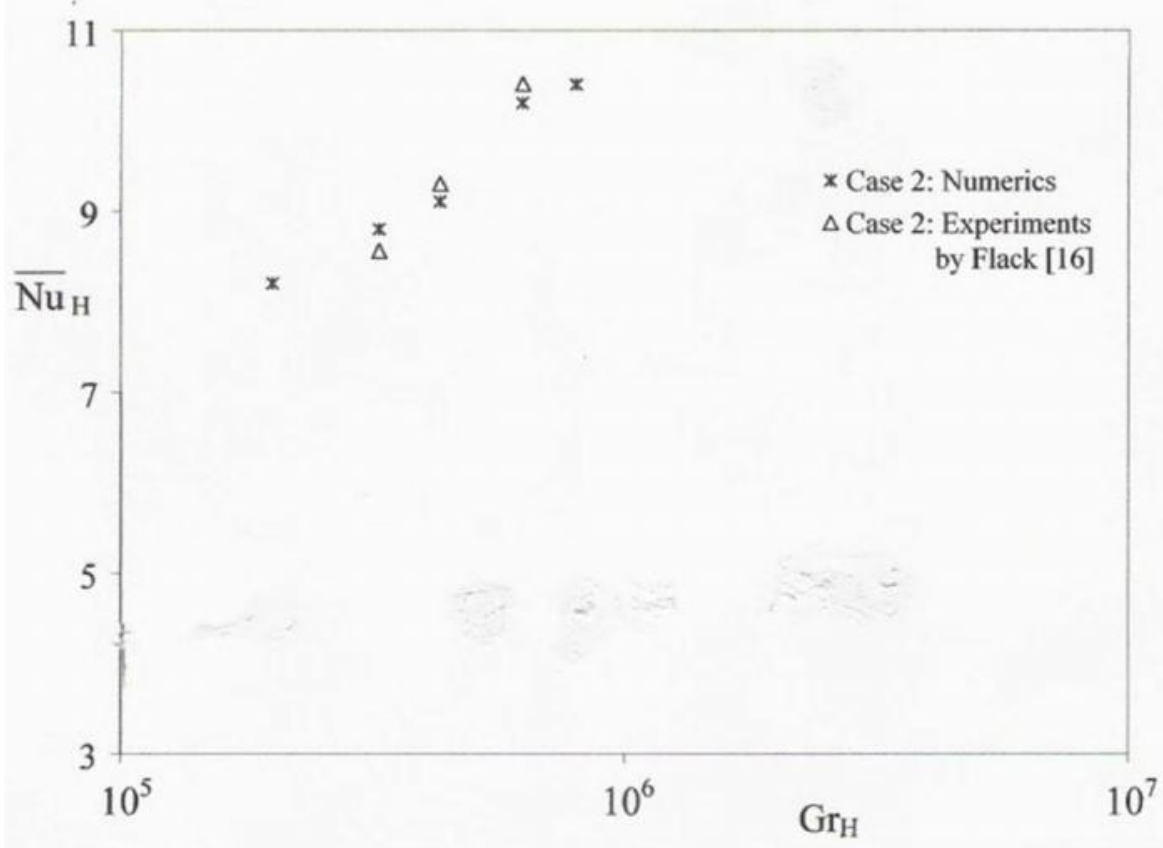

Figure 7. Comparison between the Numerical Predictions and the Experimental MeasurementsOf Mean Nusselt Number Nu H Varying With Rayleigh Number Rah For Case 1

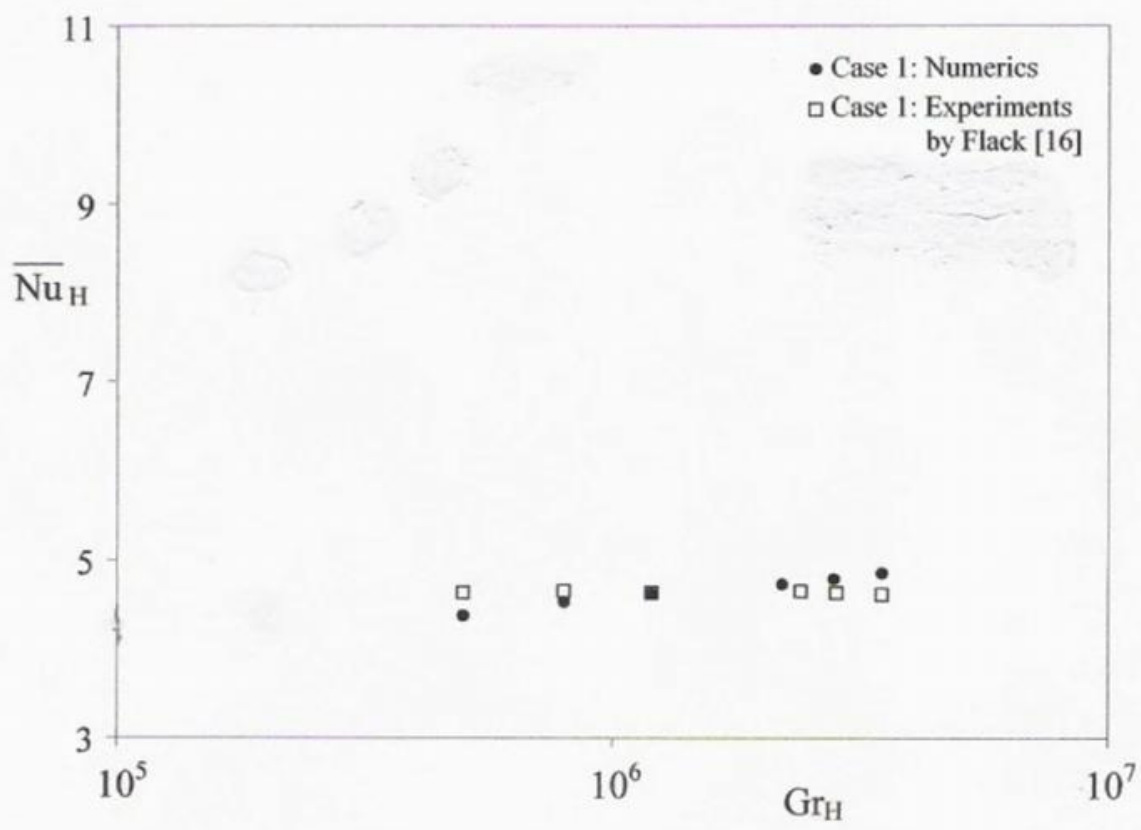

Figure 8. Comparison Between The Numerical Predictions And The Experimental Measurements of the Mean Nusselt Number $\overline{\mathrm{Nu}}$ H Varying With Rayleigh Number $\mathrm{Ra}_{\mathrm{h}}$ For Case 2 


\section{Concluding Remarks}

When the upper inclined walls of a house or building attic are symmetrically heated and the horizontal bottom walls are cooled as it happens in Case 1, the air velocities and temperatures are always stable regardless of the value assigned to $\mathrm{GrH}$. The impending result is a collection of stratified temperature profiles corresponding to the heat conduction mode. Under these circumstances, the experimental $\overline{\mathrm{Nu}}_{\mathrm{H}}$ stays around 4.5, confirming that the heat is transported in stagnant air by conduction in a relatively large GrH interval up to 107 . For Case 2 , an attic with symmetrically cooled inclined upper walls and heated bottom walls, as $\mathrm{GrH}$ increases, the flow regimes include the conduction and natural convection modes resulting in a significant increment in the mean convective coefficient $\bar{h}$ over that for pure conduction. In this regard, excellent agreement exists between the numerical predictions and the experimental measurements of $\overline{\mathrm{Nu}}_{\mathrm{H}}$. The agreement lends credibility to the finite-element based COMSOL code for the accurate prediction of the buoyant circulatory air currents in house and building attics, an important step for the quantification of heat loads. The compact comprehensive correlation equation (11) could be used by design engineers to quantify heat loads through house and building attics in building science research.

\section{Nomenclature}

\begin{tabular}{|c|c|}
\hline A & aspect ratio of attic, $\mathrm{H} / \mathrm{W}$ \\
\hline $\mathrm{cp}$ & specific isobaric heat capacity of air, $\mathrm{kJ} / \mathrm{kg} .{ }^{\circ} \mathrm{C}$ \\
\hline $\mathrm{g}$ & acceleration of gravity, $\mathrm{m} / \mathrm{s} 2$ \\
\hline $\mathrm{GrH}$ & Grashof number, $(\mathrm{g} \beta / \mathrm{v} 2)(\mathrm{TH}-\mathrm{TC}) \mathrm{H} 3$ \\
\hline $\mathrm{h}$ & mean convective coefficient, $\mathrm{W} / \mathrm{m} 2 .{ }^{\circ} \mathrm{C}$ \\
\hline $\mathrm{H}$ & height of attic, $\mathrm{m}$ \\
\hline $\mathrm{k}$ & thermal conductivity of air, $\mathrm{W} / \mathrm{m} .{ }^{\circ} \mathrm{C}$ \\
\hline $\mathrm{L}$ & length of inclined wall in attic, $m$ \\
\hline & mean Nusselt number, $\mathrm{H} \overline{\mathrm{h}}_{/ \mathrm{k}}$ \\
\hline & pressure, bar \\
\hline $\operatorname{Pr}$ & Prandtl number, $\mathrm{cp} / \mathrm{k}$ \\
\hline qw & wall heat flux, W/m2 \\
\hline $\mathrm{q}_{\mathrm{w}}$ & mean wall heat flux, W/m2 \\
\hline $\mathrm{RaH}$ & Rayleigh number, GrH Pr \\
\hline $\mathrm{T}$ & temperature, ${ }^{\circ} \mathrm{C}$ \\
\hline $\mathrm{TC}$ & cold wall temperature, ${ }^{\circ} \mathrm{C}$ \\
\hline $\mathrm{TH}$ & hot wall temperature, ${ }^{\circ} \mathrm{C}$ \\
\hline $\mathrm{u}, \mathrm{v}$ & velocities in the $\mathrm{x}-$ and $\mathrm{y}-$ directions, $\mathrm{m} / \mathrm{s}$ \\
\hline $\mathrm{x}, \mathrm{y}$ & horizontal and vertical coordinates in Fig. 1, m \\
\hline $\mathrm{z}$ & coordinate along inclined wall in Fig. 1 \\
\hline $\mathrm{W}$ & base of attic, $m$ \\
\hline
\end{tabular}

\section{Greek Letters}

$\alpha \quad$ apex angle of attic in Fig. 1

$\beta \quad$ volumetric thermal expansion coefficient for air, $1 / \mathrm{K}$

$v \quad$ kinematic viscosity of air, $\mathrm{m} 2 / \mathrm{s}$

$\theta \quad$ dimensionless temperature, $(\mathrm{T}-\mathrm{TC}) /(\mathrm{TH}-\mathrm{TC})$

$\rho \quad$ density of air, $\mathrm{kg} / \mathrm{m} 3$

$\psi \quad$ stream function $\mathrm{u}=\partial \psi / \partial \mathrm{y}, \quad \mathrm{v}=-\partial \psi / \partial \mathrm{x}$

\section{References}

[1] G. D. Raithby, K. G. D. Hollands, Natural convection: Chapter 6, in W. M. Rohsenow, J. O. Hartnett, N. Ganic (Eds.), Handbook of Heat Transfer Fundamentals, McGraw-Hill, New York, 1985.

[2] Y. Jaluria, Natural Convection: Chapter 7, in Bejan, A. and Kraus, A. D., (Eds.), Heat Transfer Handbook, New York: John Wiley, 2003.

[3] ASHRAE Handbook, American Society of Heating, Refrigeration and Air Conditioning Engineers, Atlanta, GA, 2002.

[4] M. G. Davies, Building Heat Transfer, John Wiley, New York, 2004.

[5] V. A. Akinsete, T. A. Coleman, Heat transfer by steady laminar free convection in triangular enclosures, Intern. J. Heat Mass Transfer Vol. 25 (1982) pp. 991-998.

[6] D. Poulikakos, A. Bejan, The fluid dynamics of an attic space, J. Fluid Mech. Vol. 131 (1982). 251-269.

[7] H. Salmun, Convection patterns in a triangular domain, Intern. J. Heat Mass Transfer Vol. 38 (1995) pp. 351-362.

[8] A. Holtzman, R. W. Hill, K. S. Ball, Laminar natural convection in isosceles triangular enclosures heated from below and symmetrically cooled from above. J. Heat Transfer Vol. 122 (2000) pp. 485-491.

[9] D. R. Chenoweth, S. Paolucci, Natural convection in an enclosed vertical air layer. J. Fluid Mech. Vol. 169 (1986) pp.173-210.

[10] P. H. Oosthuizen, D. Naylor, Introduction to Convective Heat Transfer Analysis, McGraw-Hill, New York, 1998.

[11] J. C. Tannehill, D. A. Anderson, R. H. Pletcher, Computational Fluid Mechanics and Heat Transfer, Taylor and Francis, Washington, DC, 1997.

[12] O. C. Zienkiewicz, R. L. Taylor, J. Z. Zhu, The Finite Element Method: Its Basis and Fundamentals, Seventh Edition, Butterworth-Heinemann, Oxford, England, 2013.

[13] COMSOL Multiphysics User's Guide, Version 3.5, COMSOL, Inc., Burlington, MA, 2008.

[14] T. A. Davis, Algorithm 832: UMFPACK V4.3-An Unsymmetric-pattern multifrontal method, ACM Transactions on Mathematical Software, 30 (2004), 196199.

[15] G. de Vahl Davis, Natural convection of air in a square cavity: a benchmark numerical solution, Intern. J. Numer. Meth. Fluids Vol. 11 (1983) pp. 249-264.

[16] R. D. Flack, The experimental measurement of natural convection heat transfer in triangular enclosures heated or cooled from below, J. Heat Transfer Vol. 102 (1980) pp. 770-772.

[17] SAS Procedures Guide, Version 6, Third edition, SAS Institute Inc., Cary, NC, 1990 